\title{
ESTUDO COMPARATIVO SOBRE A INTERAÇĀO VERBAL ENTRE ENFERMEIRAS E ATENDENTES DE ENFERMAGEM COM O PACIENTE PORTADOR DE AIDS.
}

\author{
Elucir Gir* \\ Tokico Murakawa Moriya **
}

GIR, E.; MORIYA, T.M. Estudo comparativo sobre a interação verbal entre enfermeiras e atendentes de enfermagem com o paciente portador de AIDS. Rev. Esc. Enf. USP., v. 27, n.3, p. 387-402, dez. 1993.

Objetivou-se com este trabalho identificar as áreas de comportamentos verbais, predominantemente, trocados entre enfermeiras e portadores de AIDS e entre estes pacientes e atendentes de Enfermagem; alérn de identificar e comparar os padrões de interação verbal destas duas duplas, tendo como fio norteador o System of Analysis of Verbal Interaction (SAVI). Os resultados alcançados nesse estudo mostram que predominaram e representaram fala homogênea entre os sujeitos, direcionados para comportamentos de aproximação.

Evidenciou-se também, que as enfermeiras apresentaram maior número de episódios verbais com os pacientes em estado grave, ao passo que os atendentes de Enfermagem, com os pacientes em bom estado geral.

UNITERMOS: SIDA/AIDS, Interação verbal, Enfermagem

\section{INTRODUÇÃO:}

Comunicação é um processo, instrumento ou habilidade? CARVALHO (1989), a partir de amplo levantamento bibliográfico realizado, discute que no Brasil estes dois últimos termos são considerados parassinônimos por alguns autores e como distintos, por outros. Considera, entretanto, privilegiada a designação de comunicação enquanto habilidade indispensável ao adequado exercício profissional.

Acata-se o pensar do autor mencionado, principalmente por entender a comunicação como uma forma básica e fundamental para se obter e transmitir os significados e conceitos do ser humano, em especial do doente.

\footnotetext{
- Mestre em Enfermagem, docente junto a Escola de Enfermagem de Ribeirāo Preto-USP.

* Doutor em Enfermagem, docente junto a Escola de Enfermagem de Ribeirão Preto-USP.
} 
SKIPPER (1965) expõe que uma das queixas mais freqüentes dos pacientes hospitalizados é a falta de comunicação com o pessoal que os assiste e ainda lembra que, a estrutura do hospital moderno não é organizada com vistas ao alcance da necessidade de comunicação do paciente.

Outros autores como HELWITT; PESZNECKER (1964), STOCKWELL (1972), FAULKNER (1979), MENDES (1986), CARVALHO (1989) apontam falhas na comunicação entre pacientes e equipe de enfermagem, onde em algumas destas pesquisas é reforçada a necessidade de mudança na interação entre o enfermeiro e o paciente.

Os trabalhos consultados abordam pacientes portadores de doenças agudas ou crônicas de forma geral, sendo que a literatura sobre Comunicação em Enfermagem no Campo das Doenças Transmissíveis, é restrito.

Sabe-se que a doença associada à hospitalização e principalmente quando a enfermidade é transmissível, torna a pessoa mais vulnerável a desequilíbrios emocionais. Ao se falar em AIDS, que além de transmissível é fatal e estigmatizante, CHRIST; WIENER (1985) e ROSNER et al (1985) destacam que tais portadores vivenciam rejeição e discriminação da sociedade, família e amigos.

Como refere LACAZ (1985), a AIDS trouxe à tona o medo e o pânico, levando a alteraçōes significativas das interaçōes interpessoais no contexto social em que vivem. Vem, sobretudo, modificando comportamentos, suscitando ódios, despertando preconceitos e até mesmo lendas. No âmbito hospitalar, tal fato nāo poderia repercutir de modo diferente, pois aliado ao preconceito, surgiu o medo de cuidar destes pacientes (MACIEL, 1987). GILLON (1987) e KELLY et al (1987) mencionam que muitos profissionais de saúde crêem em estigmas e até se recusam a assistir tais enfermos.

Considerando-se, portanto, as reaçōes em geral, que têm sido manifestadas em relação à AIDS e sendo que a comunicaçāo permeia todas as atividades de Enfermagem, decidiu-se identificar as áreas de comportamentos verbais predominantemente trocadas entre enfermeiras e pacientes portadores de AIDS e estes pacientes e atendentes de enfermagem, além de identificar e comparar os padrōes de interaçāo verbal destas duas duplas, tendo como fio condutor o System of Analysis of Verbal Interaction (SIMON; AGAZARIAN, 1967).

\section{METODOLOGIA:}

A coleta de dados para esta pesquisa foi realizada em enfermarias com leitos individuais da Unidade de Internaçāo de Moléstias InfectoContagiosas, de um hospital-escola de 600 leitos da cidade de Ribeirão Preto-SP, Brasil. 
Correspondeu à amostra 90 horas de observação junto a três enfermeiras e quatro atendentes de enfermagem - enquanto desempenhavam suas atividades profissionais rotineiras no período estabelecido e que entraram nas enfermarias em observação, quer por designação de escala de serviço, quer por outro motivo qualquer - e três pacientes.

Cada paciente foi observado durante 30 horas, de segunda a sextafeira, no período das 7 às 13 horas. Para a observação da interação verbal entre enfermeiras e pacientes / atendentes de enfermagem e pacientes, contou-se com quatro observadores, previamente treinados e calibrados, que se rodiziavam entre si a cada 90 minutos, de tal forma que sempre um deles se mantinha dentro da enfermaria, para proceder à observaçāo e registro dos comportamentos verbais que ocorressem, valendo-se das técnicas de observação do tipo relato cursivo e de registro com lápis e papel, cuja descrição detalhada encontra-se em GIR (1988).

A equipe de saúde, como um todo, foi informada que os autores da pesquisa iriam observar alguns aspectos na enfermaria, sem entretanto saber-se observado sobre 0 assunto comunicação com o paciente. Os propósitos detalhados da investigação foram apresentados à divisão de Enfermagem, Departamento de Clínica Médica e Comissão de Ética do hospital em questão, recebendo parecer favorável para a realização da mesma.

Elaborou-se um protocolo para cada paciente e submeteu-se a três juízes para efetuarem a divisão dos episódios verbais em unidades e a classificaçāo, segundo sistema SAVI (System of Analysis of Verbal Interaction). Cabe ressaltar que tanto os observadores como os juízes eram alunos de graduaçāo em Enfermagem do $4^{2}$ ano, que foram selecionados e especialmente treinados pelos autores para esta pesquisa.

Após a classificação de cada unidade verbal, os dados eram lançados na matriz SAVI, respeitando-se os emissores e receptores da mensagem e procedia-se a análise quantitativa dos dados.

\section{Pressupostos Teóricos do SAVI:}

Segundo SIMON; AGAZARIAN (1967), o SAVI fundamenta-se teoricamente na psicologia e constitui uma teoria unificada do comportamento de comunicação em grupo, um sistema de análise de interação, um instrumento para diagnóstico do comportamento de grupos e uma técnica para pesquisa nas ciências sociais.

É uma técnica utilizada para coletar, descrever, organizar, analisar e interpretar dados referentes ao comportamento verbal de indivíduos e grupos. Através deste sistema é possível registrar o que as pessoas fazem, quando se comunicam, de maneira tal que pode ser descrita por outras pessoas de forma objetiva e sem ambigüidade. Permite definir um grupo pelo que faz e não pelo que se espera que ele faça. 
O SAVI oferece informações a respeito da interação do grupo, a partir da interpretação da densidade de lançamento nas células ou nas áreas específicas e sua relação mútua. Outro aspecto relevante no emprego deste sistema é que ele pode preservar a informação sobre combinaçōes de pares de comportamento.

O SAVI pode ser aplicado para grupos pequenos (de duas pessoas) ou grandes (uma audiência), observados ao vivo ou sob gravação. Uma vez que o comportamento é observado, o observador categoriza-o, registra-o na matriz, sendo que pode também se considerar a seqüência do comportamento do par, conforme aconteceu.

Pela teoria SAVI, COMUNICAÇĀO é conceituada como o processo de transferir informaçōes entre pessoas, por intermédio de um sistema de comportamentos de comunicação tradicionais (aqueles padronizados durante as geraçōes) e espontâneos (aqueles internalizados em cada ser, no processo de se transformar num membro da cultura). Cada tentativa de transferir dados de uma pessoa para outra implica numa mensagem complexa e potencialmente mal compreendida.

O sistema de comunicação contém comportamentos verbais e não verbais; logo, palavras, tom de voz, movimentos corporais e postura, tato, tonus muscular, vestuários, transmitem informaçōes.

Cada ato de um comportamento verbal transmite uma mensagem, e esta contém dois tipos de informaçōes interdependentes e relacionadas. A informação racional, de conteúdo cognitivo ou informação do assunto ou tema é o tipo de informação que mais freqüentemente se pensa estar contida no comportamento verbal; relaciona-se ao quê comunicar. Esta informação é a matéria-prima para a solução do problema, uma agenda ou a realização de uma tarefa com o objetivo de produtividade. É a fonte de dados que torna disponivel para um grupo a solução de um problema. É imprescindível para a estruturação intencional de um sistema de comunicação e métodos para a solução de problemas.

A informação pessoal ou emocional ou o componente interpessoal da mensagem é a informação a respeito de como as pessoas estão se relacionando entre si. Esta constitui a matéria básica para o desenvolvimento e manutenção das relações interpessoais entre os sujeitos que se comunicam.

A mensagem pode ser ambígua, contraditória ou redundante ou ainda, clara, dependendo de quão e como relacionados os componentes da mensagem estão, além dos aspectos de que a transferência de informação depende também da qualidade e do contexto cultural do comportamento verbal.

Todo comportamento verbal categorizado pelo SAVI, é considerado como comportamento de solução do problema pelos dois critérios de:

a) Aproximacão ou Afastamento do problema e do que comunicar:

- Comportamento de Aproximacão: são os comportamentos verbais caracterizados pelo que se tem de potencial significativo para 
aproximação do problema de comunicação. Estes comportamentos transmitem mensagens relativamente "Claras" e a informação temática e pessoal contida na mensagem, ou seqüência de mensagens, é não ambígua, não contraditória e não redundante.

- Comportamentos de Afastamento: sāo os comportamentos verbais caracterizados por potencial significativo para afastamento da solução do problema de comunicação. Transmitem mensagens relativamente obscuras e nas quais as relaçōes funcionais entre os componentes pessoal e temático da informação são ambíguos e contraditórios.

- Aproximacão Potencial ou Comportamentos de Afastamento: são os comportamentos verbais potenciais para a solução de problemas caracterizados pelo potencial não significativo, para aproximação ou afastamento do problema de comunicaçāo, e o seu caráter de aproximação ou afastamento está relacionado mais com a seqüência no qual eles ocorrem, do que ato comportamental particular.

Estes comportamentos não são significativamente "claros" ou "obscuros" neles mesmos; as relações funcionais entre os componentes de informaçāo temática e pessoal são determinadas por ambigüidade, contradição ou redundância das seqüências, determinadas pela matriz da análise seqüencial.

b) Informação pessoal ou temática contida na mensagem:

- Informacão Temática: quando na mensagem, a informação temática predomina sobre a informação pessoal, a mensagem é classificada como mensagem temática e a ação é classificada como um ato de aproximação, afastamento ou aproximação potencial ou de afastamento temático.

- Informacão Pessoal: quando na mensagem, a informação pessoal sobrepõe a informação temática, a classificação é feita em mensagem pessoal, e o ato é classificado como sendo de aproximação, afastamento ou aproximação potencial ou mensagem de afastamento pessoal.

- Temática Pessoal: quando na mensagem, tanto a informação temática como a pessoal são equilibradas; a mensagem é classificada como temática pessoal e o ato é classificado como sendo de aproximação, afastamento ou como sendo mensagem potencial, para aproximação-afastamento do tema. 
- Acrescenta-se que estes comportamentos de aproximação, afastamento refletem o COMO fazer para serem criadas necessidades com o objetivo de aumentar as relaçōes de crescimento a nível interpessoal, as habilidades na solução dos problemas e a execução de tarefas criativas.

O sistema SAVI tem como fio condutor uma matriz, que é uma grade preconizada por SIMON; AGAZARIAN (1967), formada por 28 linhas e 28 colunas, que representam nove áreas de comportamentos verbais, ou sejam, A, B, C, D, E, F, G, H, J. Cada área é denominada, considerando-se que o comportamento verbal pode ser classificado como um comportamento que aproxima ou a fasta a informação pessoal e/ou temática. Em outras palavras, o comportamento de afastamento relaciona-se a mensagens contraditórias e obscuras e o de aproximação, a mensagens claras e não contraditórias.

Cada área definida por um conjunto de categorias que, no total soam 28. A matriz SAVI contém, portanto, 784 células, sendo que cada célu' corresponde a um ponto de intersecção entre duas categorias - a emitiu e a recebida (ver figura 1 na página seguinte).

\section{DEFINIÇÕES DAS CATEGORIAS E SUB-CATEGORIAS DO SISTEMA SAVI:}

01. AD-AUTO-DEFESA *: criticismo negativo ou defesa de "Self", auto-diminuição.

02. HO-HOSTILIDADE *: criticismo negativo dos outros, de objetivos, ataque verbal direto, questões e opiniões sarcásticas. Questões de ataque, questōes ofensivas que diminuem diretamente uma pessoa. Opinião negativa do material que está sendo trabalhado ou da maneira de se trabalhar com o mesmo, seja solicitado ou não.

03. NA-NARRATIVA *: anedotas, exposição dos detalhes de uma história. O relato de uma informação ou experiência pessoal que ocorreu fora do grupo.

04. OB-OBRIGATORIEDADE *: julgamentos de valor dogmático que implicam prescrições gerais do que todo mundo deveria saber ou do que todo mundo devia estar fazendo.

05. IN-INTELECTUALIZAÇÃO *: análise de um problema exclusivamente em termos intelectuais, negligenciando ou excluindo sentimentos ou considerações práticas.

06. BD-BRINCADEIRA DEFENSIVA *: piadas feitas às custas de uma pessoa, do próprio eu, ou do trabalho. 
FIGURA 1. Matriz SAVI: 9 áreas, 28 categorias, 784 células

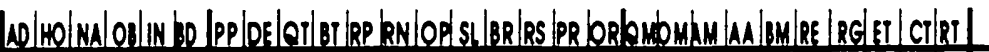

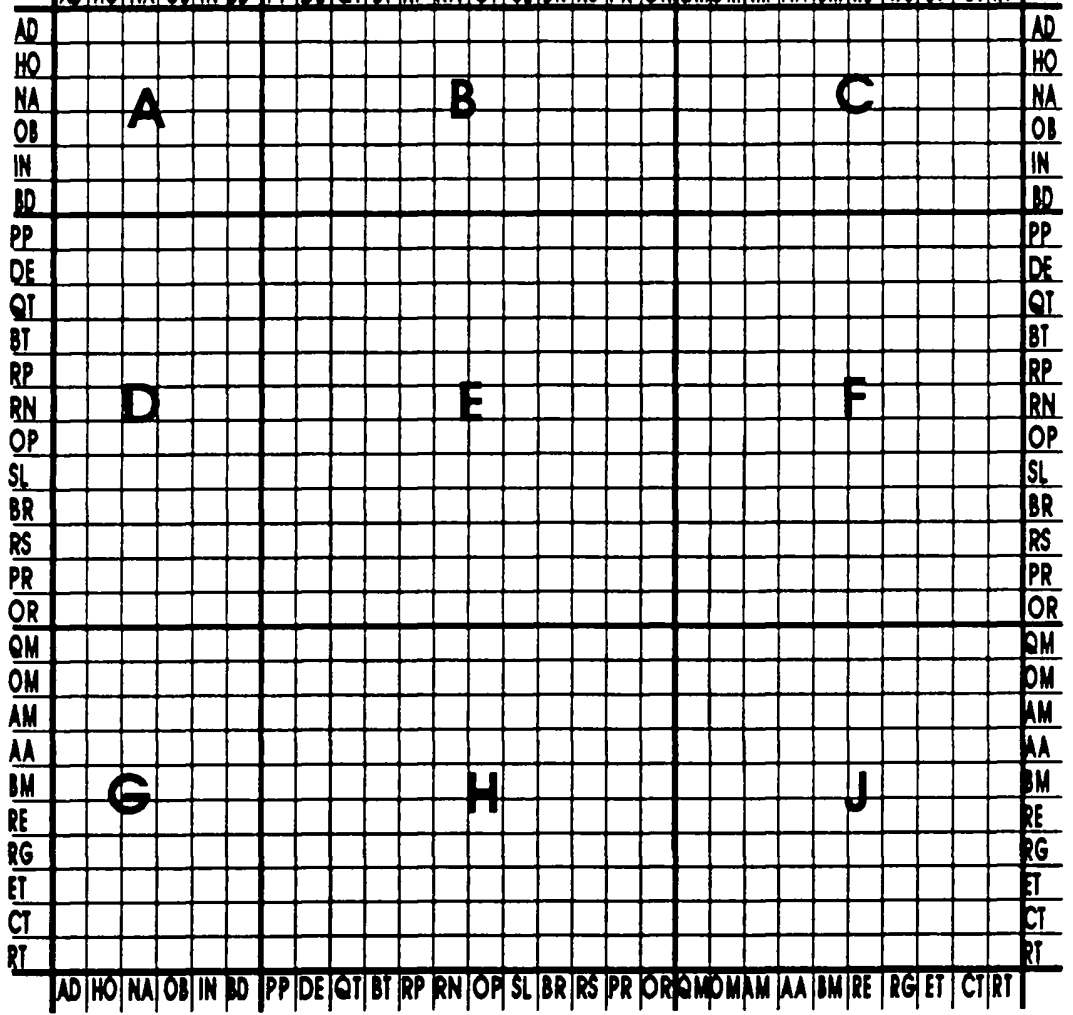

(ADAPTADO DE SIMON \& AGAZARIAN, 1967)

$A D=$ Auto Defesa; Ho = Hostilidade; NA = Narrativa; $O B=$ Obrigatoriedade; IN = Intelectualidade; $\mathbf{B D}=$ Brincadeira Defensiva; $\mathbf{P P}=$ Participação Pessoal; DE = Descrição; QT = Questāo sobre o Tema; $B T=$ Brincadeira sobre o Tema; RP = Resposta Positiva; RN = Resposta Negativa; OP = Opinião; SL = Silêncio; BR = Barulho; RS = Riso; RP = Proposta; OR = Ordem; QM = Questāo de Manutenção; $O M=$ Oferece Manutenção; $A M=$ Apoia Manutenção; $A A=$ Auto Afirma; $B M=$ Brincadeira de manutenção; $R E=$ Resposta Específica; RG = Resposta Geral; ET = Esclarecimento sobre o Tema; CT = Construção do Tema; RT - Reflexão sobre o Tema.

ÁREAS: A = Afastamento de manutençāo pessoal; $B=$ Afastamento do tema, $\mathrm{C}=$ Afastamento do tema e/ou da manutenção pessoal; $\mathrm{D}=$ Aproximação e/ou afastamento potencial de manutenção pessoal; $E$ = Aproximação e/ou afastamento potencial do tema; $F$ = Aproximação e/ou afastamento potencial do tema e/ou pessoal; $\mathrm{G}=$ Aproximação de manutenção pessoal; $\mathbf{H}=$ Aproxima ção do tema; $\mathbf{J}=$ Aproximação do tema e/ou pessoal. 
07. PP-PARTICIPAÇÃO PESSOAL *: informação pessoal a respeito do que gosta, desgosta, acontecimento ou eventos que são "íntimos" à pessoa; descriçōes pessoais de "como eu sinto, o que eu desejo" em relação ao tema ou a tarefa.

08. DE-DESCRIÇÃO *: descrição da condiçōes de objetos, atividades, comportamentos ou pensamentos.

09. OT-QUESTÃO SOBRE O TEMA *: questões de natureza não pessoal.

10. BT-BRINCADEIRA SOBRE O TEMA *: alguma coisa é dita que provoca risos; gracejos, trocadilhos a respeito do tema que se discute ou a situação na qual a discussão está ocorrendo. É não defensiva e de não-manutenção. Não inclui anedotas da vida pessoal.

11. RP-REFORÇO POSITIVO *: concorda, encoraja o locutor a continuar sua mesma linha de conversação, mas não dá outra informação que o ouvinte aprova a mensagem.

12. RN-REFORÇO NEGATIVO *: desencoraja. Tende a desencorajar o assunto que está sendo discutido e mudar a direção da conversação para longe do assunto discutido ou encaminhá-lo de uma forma diferente.

13. OP-OPINIÃO *: conclusões não apoiadas pelos fatos. Julgamentos, apreciaçōes, interpretação, especulaçōes, suposiçōes a respeito de um assunto. Implica uma conclusão que é expressada sem que seja formulada uma base explícita da qual ela é derivada.

14. SL-SILÊNCIO *: silêncio no grupo.

15. BR-BARULHO *: mais de uma pessoa fala ao mesmo tempo no grupo. Muito barulho para que o codificador ouça o que está acontecendo.

16. RS-RISOS *: os membros do grupo riem.

17. PR-PROPOSTA *: o ato de propor ou colocar alguma coisa para consideração. Tentativa de influenciar.

18. OR-ORDEM *: ordenar ou dirigir o comportamento de outro.

19. QM-QUESTĀO DE MANUTENÇÃO *: questōes que ajudam uma pessoa a esclarecer seus sentimentos sobre matéria muito significativa para ela.

20. OM-OFERECE MANUTENÇĀO *: dá informação pessoal sobre si mesmo, seja quando responde a uma pergunta ou quando oferece uma observação não solicitada. 
21. A-APOLA MANUTENÇĀO *: encoraja por uma assistência adicional, seja de natureza material ou emocional. Observa-se que apoiar emocionalmente uma pessoa e informá-la do estado do locutor, compreende como o ouvinte se sente.

22. AA-AUTO AFIRMA *: sentenças de natureza auto-declarativas do autor, afirmativas que sustentam ou mantém um propósito ou o "Self" sem serem defensivas ou hostis.

23. BM-BRINCADEIRA DE MANUTENÇÃO *: alguma coisa é dita ou feita que provoca riso. Manutenção de gracejos são piadas agradáveis que sustentam outra pessoa ou o grupo. Elas são não defensivas, sem hostilidade e sem crítica.

24. RE-RESPOSTA ESPECÍFICA *: resposta a questōes que são certas ou erradas, ou para as quais existe somente uma resposta ou um número limitado de resposta. Respostas de fato.

25. RG-RESPOSTA GERAL *: respostas às questões que exigem que as pessoas dêem uma opinião, façam inferências, avaliação, estabeleçam uma relação entre fatos ou uma série de fatos; respostas às questões para as quais não existem respostas certas ou erradas (questão de avaliação ou divergente).

26. ET-ESCLARECIMENTO DO TEMA *: esclarecimentos, expansão ou ampliação do assunto para ser trabalhado com ele imediatamente.

27. CT-CONSTRUÇĀO DO TEMA *: desenvolver ou ajudar a idéia do outro. Imediata adição de uma nova idéia que esteja estreitamente relacionada à que foi mencionada anteriormente. Implica numa concordância com o pensamento da pessoa.

28. RT-REFLEXĀO DO TEMA *: citação em paráfrase de alguma coisa dita dentro do grupo. Ela indica para o grupo que o locutor ouviu atentamente a mensagem original. Não é julgada a decisão da sentença; é a tentativa, não o conteúdo que é considerado.

\section{RESULTADOS E DISCUSSÃO:}

Foram identificados 1330 episódios verbais, dos quais 768 foram tracados entre pacientes e atendentes e 562 entre pacientes e enfermeiras, cuja distribuição encontra-se na TABELA 1. 


\begin{tabular}{|l|c|c|}
\hline \multirow{2}{*}{ TABELA 1 - Distribuição das Freqüèncias dos Episódios verbais segundo interaçäo entre } \\
pacientes e atendentes de enfermagem ou pacientes e enfermeiras. \\
\hline PACIENTES & \multicolumn{2}{|c|}{ PROFISSIONAL DE ENFERMAGEM } \\
\cline { 2 - 3 } & Atendentes & Enfermeiras \\
\hline$P_{1}$ & $301(39,19)$ & $288(40,56)$ \\
$P_{2}$ & $147(19,14)$ & $251(44,66)$ \\
$P_{3}$ & $320(41,66)$ & $83(14,76)$ \\
\hline TOTAL & $768(57,74)$ & $562(42,25)$ \\
\hline
\end{tabular}

O número de episódios verbais ocorridos entre os atendentes e pacientes, foi mais do que entre os enfermeiros e pacientes. Este fato provavelmente se deve à modalidade de assistência empregada no hospital onde as observaçōes foram realizadas, que conforme EVORA (1984) destaca, é a funcional.

De acordo com TREVIZAN (1986), o trabalho de enfermagem viabiliza-se segundo os princípios de modelo burocrático, onde ao atendente e ao auxiliar de enfermagem, em suas escalas de serviço, são delegadas tarefas, sobretudo de assistência ao paciente, considerando-se o grau de complexidade e competência profissional.

À enfermeira - como líder da equipe de enfermagem - cabe, além da função assistencial, a de supervisão e administração do cuidado prestado na unidade, planejamento, avaliação e educação em serviço, ou seja, múltiplas funçōes, ficando a assistência direta diluída em outras atividades.

GIR (1988) demonstrou em seu estudo de interação verbal entre a equipe de enfermagem e pacientes aidéticos, que o tempo de permanência dos atendentes, dentro das enfermarias, em assistência ao paciente com AIDS, foi praticamente o mesmo tempo dispensado pelas enfermeiras; evidenciou que o auxiliar de enfermagem é o profissional da equipe de enfermagem que mais permanece com o paciente e é praticamente ele quem presta assistência direta ao paciente.

Para maior compreensão dos dados da TABELA 1, merece ser comentada ainda, a condição geral dos pacientes. $O$ paciente $P_{1}$ apresentava dores óssea e abdominal intensa e estava extremamente queixoso e dependente da equipe de enfermagem. $\mathrm{O}$ aspecto geral de $\mathrm{P}_{2}$ era precário; apresentava-se bastante queixoso pela varicela disseminada e sua dependência da equipe de enfermagem era parcial. $\mathrm{P}_{3}$ encontrava-se em melhores condiçōes gerais, desenvolvendo auto-cuidados, independente da equipe de enfermagem.

O estado geral do paciente leva a acreditar que este foi um fator determinante para a maior permanência e atuação direta da enfermeira junto aos pacientes mais graves; o que foi revelado pela quantidade de comportamentos verbais traçados. $O$ atendente manifes tou mais comportamentos verbais com $\mathrm{P}_{3}$, que era quem se encontrava em melhores 
condiçōes gerais. Estes resultados são pertinentes às atribuiçōes profissionais destes elementos de acordo com a sua complexidade.

Visando identificar os padrōes de interação verbal entre enfermeiras e pacientes e atendentes de enfermagem e pacientes, procedeu-se ao lançamento dos 1330 episódios verbais em 6 matrizes SAVI, cada uma composta por 4 quadrantes, levando-se em conta o emissor e o receptor da mensagem.

A fim de permitir uma visualização geral da distribuição destes comportamentos verbais, elaborou-se o QUADRO 1 (ver página seguinte), distribuindo os comportamentos, de acordo com as matrizes, quadrantes e áreas da matriz SAVI.

$\mathrm{Da}$ interação verbal entre as enfermeiras e pacientes, tem-se que as áreas que retiveram maior número de comportamentos verbais, foram as áreas $\mathrm{E}$ (aproximação e/ou afastamento potencial do tema), $\mathrm{F}$ (aproximação e/ou afastamento potencial do tema e/ou pessoal), $\mathrm{H}$ (aproximação do tema), J (aproximação do tema e/ou pessoal). Entre os atendentes e pacientes, a seqüência foi $\mathrm{E}$. H. F. J.

Portanto, o padrão de interação verbal identificado foram as seqüências E. F. H. J., para enfermeira e pacientes e E. H. F. J. para atendentes e pacientes. Este resultado na verdade corresponde a uma fração de um estudo maior realizado por GIR; MORIYA (1990) que norteados pelo sistema SAVI analisaram a interação verbal entre a equipe de enfermagem, sem especificação e os portadores de AIDS onde detectaram as mesmas quatro áreas do comportamento verbal.

GIR; MORIYA (1990) estudando a interação verbal entre a equipe de enfermagem e os portadores de AIDS detectaram resultados semelhantes no que refere as áreas prioritárias.

Ver quadro na página ao lado

Para SIMON; AGAZARIAN (1967), a área E traduz os comportamentos que conduzem mensagens com potencial de serem usadas pelo grupo. Alguns dos comportamentos que aparecem na área $\mathrm{E}$ são falas que expressam opiniāo, descrição, compartilhar informaçōes pessoais sobre sua própria história de vida ou estado mental e propósitos. O uso destas categorias aumenta a informação pessoal de que o grupo dispōe.

A área $\mathrm{F}$ mostra como o grupo reage às novas informações, sendo trazidas para ele. A área $\mathrm{H}$ indica que os elementos estão se distanciando dos comportamentos de afastamento e produzindo, potencialmente, novas fontes de recursos dentro do grupo.

A área $J$ representa os comportamentos de sentimentos, apoiar alguém em nível pessoal, a estruturar, esclarecer ou aceitar idéias, que contribuam para uma solução de problemas de manutenção e tarefa do grupo. Forte concentração nesta área indica que o grupo es tá trabalhando para melhorar sua eficiência interpessoal, aumentando a habilidade de comunicação; oferecendo oportunidade para expressar sentimentos e considerar os "feedivacks", é uma área fortemente positiva, que neste estudo apareceu em $4^{Q}$ lugar dentre as áreas mais predominantes. 
QUADRO 1 - Distribuição dos Comportamentos verbais segundo Matriz, Quadrantes e áreas da Matriz SAVI.

\begin{tabular}{|c|c|c|c|c|c|c|c|c|c|c|c|c|}
\hline \multirow[t]{2}{*}{ MATRIZ } & \multirow{2}{*}{$\begin{array}{l}\text { QUADRANTE } \\
\text { SEGUNDO } \\
\text { EMISSOR E } \\
\text { RECEPTOR }\end{array}$} & \multicolumn{9}{|c|}{ ÁREAS DA MATRIZ SAVI } & \multirow{2}{*}{$\begin{array}{c}\text { TOTAL } \\
\text { POR } \\
\text { QUADRANTE }\end{array}$} & \multirow{2}{*}{$\begin{array}{c}\text { TOTAL } \\
\text { POR } \\
\text { MATRIZ }\end{array}$} \\
\hline & & A & B & C & D & $E$ & $\mathbf{F}$ & G & $\mathrm{H}$ & $\mathbf{J}$ & & \\
\hline \multirow[t]{4}{*}{$P_{1}-$ Enf } & $P_{1}-$ Enf & 0 & 0 & 0 & 0 & 34 & 2 & 1 & 19 & 7 & \multirow{4}{*}{$\begin{array}{l}63 \\
10 \\
93 \\
62\end{array}$} & \multirow{4}{*}{228} \\
\hline & $P_{1} \cdot P_{1}$ & 0 & 0 & 0 & 0 & 5 & 0 & 0 & 4 & 1 & & \\
\hline & Enf - Enf & 0 & 2 & 0 & 1 & 65 & 12 & 0 & 10 & 3 & & \\
\hline & Enf $-P_{1}$ & 0 & 0 & 0 & 0 & 24 & 27 & 0 & 7 & 4 & & \\
\hline \multirow[t]{4}{*}{$P_{2}$-Enf } & $P_{2} \cdot$ Enf & 0 & 0 & 1 & 0 & 23 & 11 & 0 & 26 & 9 & \multirow{4}{*}{$\begin{array}{l}70 \\
20 \\
95 \\
66\end{array}$} & \multirow{4}{*}{251} \\
\hline & $\mathbf{P}_{2} \cdot \mathbf{P}_{2}$ & 1 & 0 & 0 & 1 & 7 & 4 & 0 & 5 & 2 & & \\
\hline & Enf - Enf & 0 & 1 & 0 & 1 & 46 & 21 & 0 & 17 & 9 & & \\
\hline & Enf - $P_{2}$ & 0 & 0 & 0 & 0 & 20 & 21 & 0 & 10 & 15 & & \\
\hline \multirow[t]{4}{*}{$P_{3}-E n f$} & $P_{3}-$ Enf & 0 & 0 & 0 & 0 & 11 & 7 & 0 & 9 & 4 & \multirow{4}{*}{$\begin{array}{l}31 \\
11 \\
14 \\
27\end{array}$} & \multirow{4}{*}{83} \\
\hline & $\mathbf{P}_{3}-\mathbf{P}_{3}$ & 0 & 0 & 0 & 0 & 3 & 2 & 0 & 6 & 0 & & \\
\hline & Enf - Enf & 0 & 0 & 0 & 0 & 5 & 2 & 0 & 5 & 2 & & \\
\hline & Enf $-P_{3}$ & 0 & 0 & 0 & 0 & 8 & 11 & 0 & 2 & 6 & & \\
\hline & TOTAL & 1 & 3 & 1 & 3 & 251 & 120 & 1 & 120 & 62 & 562 & \\
\hline \multirow[t]{4}{*}{$P_{1}-A t$} & $\mathrm{P}_{1}-\mathrm{At}$ & 0 & 0 & 0 & 0 & 45 & 15 & 0 & 19 & 3 & \multirow{4}{*}{$\begin{array}{c}82 \\
12 \\
127 \\
80\end{array}$} & \multirow{4}{*}{301} \\
\hline & $P_{1} P_{1}$ & 0 & 0 & 0 & 0 & 9 & 1 & 0 & 2 & 0 & & \\
\hline & At - At & 1 & 0 & 1 & 0 & 77 & 19 & 1 & 21 & 7 & & \\
\hline & At $-P_{1}$ & 0 & 0 & 0 & 0 & 46 & 19 & 0 & 11 & 4 & & \\
\hline \multirow[t]{4}{*}{$\mathrm{P}_{2}-\mathrm{At}$} & $\mathbf{P}_{\mathbf{2}}-\mathbf{A t}$ & 0 & 0 & 0 & 0 & 28 & 8 & 0 & 13 & 2 & \multirow{4}{*}{$\begin{array}{l}51 \\
18 \\
33 \\
45\end{array}$} & \multirow{4}{*}{147} \\
\hline & $P_{2}-P_{2}$ & 0 & 0 & 0 & 0 & 3 & 3 & 0 & 11 & 1 & & \\
\hline & At - At & 0 & 0 & 0 & 0 & 21 & 6 & 0 & 4 & 2 & & \\
\hline & At $-\mathbf{P}_{2}$ & 0 & 0 & 0 & 0 & 13 & 17 & 0 & 12 & 3 & & \\
\hline \multirow[t]{4}{*}{$P_{3} \cdot$ At } & $P_{3}-A t$ & 0 & 0 & 0 & 0 & 64 & 13 & 0 & 28 & 8 & 113 & \multirow{4}{*}{320} \\
\hline & $P_{3}-P_{3}$ & 0 & 0 & 0 & 0 & 16 & 7 & 0 & 15 & 1 & 39 & \\
\hline & At - At & 0 & 0 & 0 & 0 & 43 & 14 & 1 & 12 & 2 & 72 & \\
\hline & At $-\mathbf{P}_{\mathbf{3}}$ & 0 & 0 & 1 & 0 & 39 & 34 & 0 & 11 & 11 & 96 & \\
\hline \multicolumn{2}{|l|}{ TOTAL } & 1 & 0 & 2 & $\mathbf{0}$ & 404 & 156 & 2 & $16 \theta$ & 44 & 768 & \\
\hline \multicolumn{2}{|l|}{$\begin{array}{l}\text { TOTAL } \\
\text { GERAL }\end{array}$} & 2 & 3 & 3 & 3 & 658 & 278 & $\mathbf{3}$ & 279 & 106 & 1330 & \\
\hline
\end{tabular}


As áreas $\mathrm{E}$ e $\mathrm{F}$ revelam portanto, que a comunicação ocorrida entre os pacientes portadores de AIDS e elementos da equipe de enfermagem, apresentam comportamento significativamente claros ou obscuros neles mesmos, isto é, as relaçōes funcionais entre os componentes da informação temática e/ou pessoal são determinados por relativa ambigüidade ou contradição. Estas áreas preenchidas demonstram que o emissor busca informaçōes, introduz senso de humor, expõe sua preferência e sentimentos, permitindo certa abertura a esta interaçāo e é uma situação da qual o paciente, principalmente, se beneficia ao lê-la. Nas áreas $\mathrm{H}$ e $\mathrm{J}$ tem-se por outro lado, a evidência de comportamentos verbais e cujas mensagens são relativamente claras, não ambígüas, nem contraditórias, quer seja nas relações funcionais entre os componentes da informação temática e temática e/ou pessoal. Seria ideal se a área $J$ tivesse ocorrido em primeiro lugar de freqüência, entretanto neste estudo, esta área figura em quarto lugar, segundo predominância seqüencial.

Estas áreas indicam comportamentos claros e claros e/ou obscuros neles mesmos, que permitem abertura para a interaçāo e comparando-se ambos os padrões, deduz-se que a fala dos profissionais de enfermagem e os pacientes com AIDS tende ao lado positivo e é homogênea, levando-se em consideração apenas a análise das áreas da matriz SAVI. Se os dados fossem analisados pelas categorias e sub-categorias SAVI, provavelmente detalhes seriam encontrados que indicariam a diferença qualitativa das falas dos profissionais, dado o seu nível de formação.

A homogeneidade aqui obtida deve-se, dentre outros fatores, aos cursos de treinamento e reciclagem que a equipe recebeu.

Parece positivo ter atingido padrões de comportamentos que variam de relativa ambigüidade quanto à clareza das mensagens limpas e não contraditórias. Destaca-se ainda, outro aspecto favorável, o da quase inexistência de comportamentos de afastamento, os que apregoam mensagens obscuras e cujas relaçōes funcionais entre os componentes pessoal e temático da informação são ambígüos e contraditórios (área A, B, C, D).

É reconhecida a inexistência de um sistema de comportamento verbal que trate, especificamente, da situação hospitalar e Enfermagem. A utilização dos instrumentos existentes é pertinente mediante adequação e/ou validação, conforme se pode constatar em CARVALHO (1979) que estudou a interação verbal enfermeiro-paciente, durante o procedimento de punção venosa, valendo-se do paradigma de KNINNER. MENDES (1986), pesquisou a interação verbal em situaçōes de enfermagem hospitalar, baseando-se na paradigma de BALES; SCOCHI (1986), investigou as informações verbalizadas pelas puérperas no que diz respeito à higiene alimentar do recém-nascido, utilizandose da análise de conteúdo. GIR (1988) entretanto, aponta que não encontrou na literatura de Enfermagem, nenhum trabalho cujo fio condutor tenha sido o sistema SAVI. Em decorrência a este ponto, releva-se a importincia que a diversificação de empregos de instrumentos oferece, tanto em termos de proporcionar alternativas de esco- 
lha para estudos e reprodução de investigações, como no aspecto de permitir que situações semelhantes sejam analisadas e estudadas sob diversos enfoques.

GIR; MORIYA (1990) consideraram que o SAVI é pertinente para estudos interativos em enfermagem que visem ao diagnóstico e monitorização dos comportamentos verbais através de categorização.

Permite que a análise seja feita através da utilizaçāo das 28 categorias ou menos, e suas sub-categorias, ou não, dependendo do tipo de estudo.

A partir daí pode-se diagnosticar as categorias verbais, sub-categorias ou comportamentos verbais mais predominantemente encontrados, bem como diagnosticar as áreas de comportamentos sobressalentes e sub-áreas. É possível ainda estudar as linhas e colunas predominantemente preenchidas na matriz.

As áreas prioritárias de freqüência de comportamentos verbais, segundo SAVI, foram E. F. H. J para enfermeiras e pacientes e E. H. F. $J$ para atendentes e pacientes, os quais representam fala homogênea dos profissionais e pacientes, independente do estado geral do paciente.

A quantidade de episódios verbais, entretanto, teve influência do estado geral do paciente, sendo que a enfermeira trocou comportamentos verbais com os pacientes em estado grave e os atendentes com o paciente em bom estado geral.

Ressalta-se a importância dos cursos de treinamento e reciclagem e educação continuada, para a melhoria e manutenção de um processo de comunicação efetivo e positivo.

GIR, E.; MORIYA, T.M. A comparative study concerning the verbal interaction between nurses and nursing attendants versus the AIDS patient. Rev. Esc. Enf. USP., v. 27, n.3, p. 387-402, dec. 1993.

The Objetives of this article were to identify the areas of verbal behavior, predominantly, exchanged between nurses versus AIDS partients and nursing attendants versus AIDS patents and to identify and compare the patterns of verbal interaction of both groups. The analysis were made based on the System of Analysis of Verbal Interaction (SAVI).

The results show that the areas that took precedence suggested homogeneos speaking among the people studied. It was also attested that the nurses had a greater number of verbal acts with the patientes in serious health condition, whereas the nursing attendants presented a great number of verbal acts with the patients is a good general health condition.

UNITERMS: AIDS, Verbal interaction, Nursings 


\section{REFERÊNCIAS BIBLIOGRÁFICAS}

CARVALHO, E.C. Comportamento verbal e enfermagem: a interação verbal enfermeiropaciente durante o procedimento de punçäo venosa. Ribeirão Preto, 1979. 110p. Dissertaçāo (Mestrado)-Escola de Enfermagem de Ribeirão Preto, Universidade de São Paulo.

CARVALHO, E.C. Enfermagem e comunicação: a interface. Ribeirão Preto, 1989. 245p. Tese(Livre-Docência)-Escola de Enfermagem de Ribeirão Preto, Universidade de São Paulo.

CHRIST, G.H.; WIENER, L.S. Psychosocial issues in AIDS. In: DE VITA Jr.,V. et al. AIDS: etiology, diagnosis, treatment and prevention. Philadelphia, Lippincott, 1985. p.275-97.

ÉVORA, Y.D.M. A propósito do trabalho de equipe no serviço de enfermagem. Rev.Paul.Hosp., v.32, n.1/2, p.37-40, 1984.

FAULKNER, A. Monitoring nurse-patient conversation in a ward. Nurs.Times, v.75, n.23, p. 95-6, 1979.

GILLON, R. Refusal to treat AIDS and Hiv positive patients. Br.Med.J., v.294, n.6583, p. $1332-3,1987$.

GIR, E. Interaçāo verbal entre equipe de enfermagem e pacientes aidéticos. Ribeirão Preto, 1988. 21p. Dissertaçáo (Mestrado)-Escola de Enfermagem de Ribeirão Preto, Universidade de Sāo Paulo.

GIR, E.; MORIYA, T.M. Interação verbal entre a equipe de enfermagem e o paciente aidético., Rev.Esc.Enf.USP., v.24, n.2, p.301-13, 1990.

GIR, E. et al. SAVI instrumento de pesquisa alternativo para estudos de interação verbal-estrutural teórica In: SIMPÓSIO BRASILEIRO DE COMUNICAÇÄO EM ENFERMAGEM, 2,Ribeirāo Preto, 1990. Anais, Ribeirão Preto, 1990. p.423-40.

HELWITT, H.E.; PESZNECKER,B.L. Blocks to communicating with patients. Am.J.Nurs., v.64, n.7, p. 101-3, 1964.

KELLY, J.A. et al. Stigmatization of AIDS patients by physicans. Am.J.Public.Health., v.77, n.7, p.789-91, 1987.

LACAZ, C.S. AIDS: doutrina, aspectos iatrofilosóficos, infecçóes oportunisticas associadas. São Paulo, Sarvier, 1985.

MACIEL, P.M.A. Os enfermeiros frente ao paciente com síndrome de imunodeficiência adquirida (SIDA/AIDS): uma proposta de assisténcia de enfermagem. Rio de Janeiro. 1987. 151p. Dissertaçāo (Mestrado)-Escola de Enfermagem Ana Neri, UFRJ.

MENDES, I.A.C. Interação verbal em situações de enfermagem Hospitalar: enfoque humanistico. Ribeirão Preto, 1986.175p. Tese (Doutorado)-Escola de Enfermagem de Ribeirão Preto, Universidade de Sáo Paulo.

ROSNER, F. et al. Psychusocial care team for patients with AIDS in a municipal hospital. JAMA, v.253, n.16, p. 2361, 1985. 
SCOCHI, C.G.S. Higiene alimentar do recém-nascido: estudo das informaçōes verbalizadas pelas puérperas. Ribeirāo Preto, 1986,199p. Dissertação (Mestrado)-Escola de Enfermagem de Ribeirāo Preto, Universidade de São Paulo.

SIMON, A.; AGAZARIAN, Y. Sequential analysis of verbal interaction. Philadelphia, s.ed., 1967.

SKIPPER Jr, J.K. Communication and the hospitalizes patient. In: SKIPPER Jr., J.K.; LEONARD, R.C. Social interaction and patient care. Philadelphia, J.B.Lippincott, 1965. p.61-2.

STOCKWELL, E. The unpopular patient. London, Royal College of Nursing, 1972. apud CLARK, J.M. Communication in nursing. Nurs.Times, v.77, n.1, p.12-8, 1991.

TREVIZAN, M.A. A função administra tiva da enfermeira de instituição hospitalar burocratizada. Ribeirão Preto, 1986, 200p. Tese (Doutorado)-Escola de Enfermagem de Ribeirão Preto, Universidade de São Paulo. 